\title{
INTERFACE ENTRE SAÚDE E EDUCAÇÃO NO PROCESSO DE INCLUSÃO ESCOLAR
}

\section{INTERFACE BETWEEN HEALTH AND EDUCATION IN THE SCHOOL INCLUSION PROCESS}

\section{INTERFAZENTRE SALUD Y EDUCACIÓN EN EL PROCESO DE INCLUSIÓN ESCOLAR}

Meriele Sabrina de Souza ${ }^{1}$, Rhillary Lorrayne de Souza ${ }^{1}$, Nayara Cristine Protte de Paula ${ }^{1}$, Patrícia Pinto Braga ${ }^{2}$

\section{RESUMO}

Objetivo: Analisar como se configura a articulação entre profissionais da educação, da saúde e familiares no processo de inclusão escolar. Método: Estudo qualitativo interpretativo, orientado pelo referencial de Boaventura de Sousa Santos que contou a com participação de 43 entrevistados. As entrevistas guiadas por roteiro semiestruturado foram submetidas à análise de conteúdo. Resultados: A análise permitiu identificar três categorias: a família no contexto da inclusão escolar e a relação com a escola; a atenção à criança no Sistema Único de Saúde na perspectiva dos profissionais da educação e a desarticulação entre profissionais da educação e da saúde. Conclusão: Há ausência de interação entre a enfermagem e outros profissionais de saúde com a educação. Na perspectiva dos profissionais da educação e dos cuidadores, as dificuldades relacionadas aos atendimentos de saúde no SUS, como a demora dos procedimentos e a falta de especialistas, constituem-se em desafios para o processo de inclusão, considerando que conhecer a condição da criança é um aspecto que favorece adaptações ao seu processo de aprendizagem. Os profissionais reconhecem que, no cenário de investigação, a articulação entre profissionais da educação e da saúde poderia contribuir, consideravelmente, para o aprendizado infantil. Entretanto este estudo ressalta a importância da atuação do enfermeiro no cenário da inclusão escolar com equipe multidisciplinar.

Descritores: Crianças com deficiência; Educação especial; Inclusão educacional; Enfermagem.

\section{ABSTRACT}

Objective: To analyze how the articulation between education and health professionals and family in the process of school inclusion is configured. Method: Qualitative interpretive study in which 43 participants were interviewed. The interviews guided by a semi-structured script were submitted to content analysis. Results: The analysis revealed three dimensions: Attention to the child in the Unified Health System from the perspective of the education professionals, the disarticulation between education and health professionals and the family in the context of school inclusion and the relationship with the school. Conclusion: There is no interaction between health professionals and education. From the perspective of education professionals and caregivers, the difficulties related to health care, such as delayed procedures and the lack of specialists, contribute to children's learning process. Moreover, nursing, as a science of care, is an important part in the scenario of school inclusion aiming at acting on disease prevention and health promotion.

Descriptors: Children with disabilities; Special education; Educational inclusion; Nursing.

\section{RESUMEN}

Objetivo: Analizar cómo se configura la articulación entre profesionales de la educación, de la salud y familiares, en el proceso de inclusión escolar. Método: Estudio cualitativo interpretativo en el que se entrevistó a 43 participantes. Las entrevistas conducidas por un guion semiestructurado se sometieron a un análisis de contenido. Resultados: El análisis reveló tres dimensiones: La atención al niño en el Sistema Único de Salud en la perspectiva de los profesionales de la educación, la desarticulación entre profesionales de la educación y de la salud y la familia en el contexto de la inclusión escolar y la relación con la escuela. Conclusión: Hay ausencia de interacción entre los profesionales de salud y educación. En la perspectiva de los profesionales de la educación y de los cuidadores las dificultades relacionadas a las atenciones de salud como la demora de los procedimientos y falta de especialistas contribuyen a niños sin diagnósticos o realizados tardíamente. Además, la enfermería, como ciencia de la atención, es una pieza importante en el escenario de inclusión escolar, con el objetivo de actuar en la prevención de enfermedades y la promoción de la salud.

Descriptores: Niño con discapacidad; Educación especial; Inclusión educativa; Enfermería.

${ }^{1}$ Graduanda em Enfermagem pela Universidade Federal de São João del Rei. ${ }^{2}$ Pós doutorado em Enfermagem pela Universidade Federal de Minas Gerais. Professora adjunta do curso de Enfermagem da Universidade Federal de São João del Rei.

\section{Como citar este artigo:}

Souza MS,Souza RL,Paula ,NCP , et al. Interface entre saúde e educação no processo de inclusão escolar. Revista de Enfermagem do Centro Oeste Mineiro. 2020;10:e3550. [Access ]. Available in. DOI: http//doi.org/10.19175/recom.v10i0.3550 


\section{INTRODUÇÃO}

Poucos países dispõem de informações confiáveis sobre quantas crianças possuem deficiências, quais são ou de que forma elas afetam sua vida. Essa escassez de dados prejudica o planejamento de ações voltadas para este público ${ }^{(1)}$.Estima-se que, no Brasil, pelo menos $10 \%$ das crianças nascem ou adquirem algum tipo de deficiência de natureza física, mental, intelectual ou sensorial com repercussões no desenvolvimento neuropsicomotor e 70 a $80 \%$ das sequelas poderiam ser evitadas ou minimizadas, por meio de condutas e procedimentos simples de baixo custo e de possível operacionalização com diagnóstico oportuno e medidas preventivas adequadas aos diferentes níveis de atenção ${ }^{(2)}$.

Buscando, dentre outros objetivos, promover e proteger a saúde da criança, em 2015, foi instituída pela portaria no 1.130 do Ministério da Saúde (MS) a Política Nacional de Atenção Integral à Saúde da Criança (PNAISC) ${ }^{(2)}$. Esse documento destaca que é necessário reconhecer que a promoção da qualidade de vida da criança com deficiência está diretamente relacionada à promoção e proteção de seus direitos, à inclusão aos serviços de saúde, à educação, à assistência social, entre outros, para que se desenvolva, dentro de suas possibilidades, nos primeiros anos de vida ${ }^{(2)}$.

A discussão acerca das repercussões da deficiência na infância para a família e à sociedade requer uma reflexão sobre quais estratégias são utilizadas para o exercício da cidadania e garantia de convivência e inclusão social deste grupo infantil. Nesse sentido, é oportuna uma análise sobre como vem se configurando o processo de inclusão escolar dessas crianças e como profissionais da saúde, dentre eles a enfermagem, podem contribuir com este processo.

Atualmente, pessoas com deficiência têm seus direitos educacionais garantidos pela lei 12.796 de 4 de abril de 2013, que dispõe, entre outros aspectos, sobre as diretrizes e bases da educação nacional e formação dos profissionais da educação, apresentando especificidades para pessoas com deficiência ${ }^{(3)}$ e a lei 13.146 de 6 de julho de 2015, que trata da inclusão da pessoa com deficiência ${ }^{(4)}$. Apesar dessa legislação, a literatura sinaliza que muitos desafios estão presentes no cenário brasileiro de inclusão escolar de crianças com deficiência. Identifica-se dificuldade por parte dos professores em compreender o significado de inclusão, desconhecimento do papel da escola no processo, ausência de recursos didáticos que atendam as demandas dos alunos com deficiência, superlotação nas salas de aula, dentre outros ${ }^{(5-7)}$.

É oportuno mencionar que, em 2007, foi instituído pelo Ministério da Saúde e Educação o Programa Saúde na Escola (PSE) que tem por objetivo promover ações, no ambiente escolar, que visem à promoção e prevenção da saúde de crianças e adolescentes. Neste sentido, reconhece-se que a enfermagem deve atuar diretamente na escola, assim como as outras categorias profissionais que compõem a Estratégia de Saúde da Família (ESF), serviço de saúde que se encontra mais próximo da escola, a fim de avaliar as condições de saúde das crianças e adolescentes; realizar atividades de promoção à saúde e prevenção dos agravos; e a educação permanente e capacitação dos profissionais da educação ${ }^{(8)}$.

Nesta perspectiva, segue-se a premissa de que a articulação oportuna entre educadores e profissionais de saúde poderá contribuir com o processo de inclusão escolar, especialmente quando se indicam crianças com alto grau de dependência para o autocuidado, mobilidade e função social. Destaca-se, ainda, a escassez de estudos nacionais quanto às ciências da saúde, que revelem como se configura a articulação entre educadores, profissionais de saúde e familiares no processo de cuidados e favorecimento da inclusão escolar da criança com deficiência múltipla.

Os desafios relacionados à vida cotidiana das famílias, no manejo e cuidados à criança com deficiência, aliados às fragilidades na atenção à saúde e na inclusão escolar deste público, sinalizam a relevância e pertinência em pesquisas, como esta a fim de contribuir com a apresentação de dados que possam favorecer um planejamento adequado. Consideram-se as necessidades de saúde e demandas por cuidados apresentadas pelas crianças com deficiência no cenário de investigação e como os profissionais da saúde podem contribuir no processo de inclusão escolar.

Diante dos desafios apresentados, o estudo surgiu do seguinte questionamento: como se configura a articulação entre os profissionais de saúde, da educação e família no processo de inclusão escolar de crianças com deficiência? De acordo com o exposto, o objetivo foi analisar 
como se configura a articulação entre profissionais da educação, saúde e família no processo de inclusão escolar.

\section{MÉTODOS}

Trata-se de um estudo qualitativo interpretativo que buscou os significados atribuídos pelos participantes às experiências vividas no cotidiano de inclusão escolar de crianças com deficiência. A potencialidade de estudos desta natureza é sua capacidade de fornecer descrições textuais complexas de como as pessoas experimentam uma determinada situação e produzir dados culturalmente específicos e contextualmente ricos ${ }^{(9)}$.

Adotou-se o referencial teórico, que nos convida a sair de um estado de convencimento ou naturalização das diferenças e desigualdades sociais, apostando na renovação das teorias críticas e na reemancipação social ${ }^{(10)}$. Essas transformações constroem-se, quando se buscam novas possibilidades de organização da sociedade, tornando-a mais includente, superando a reificação do presente, sem, contudo abandonar um projeto de futuro ${ }^{(10)}$. Nesse sentido, o teórico nos convoca a recusar uma lógica do pensamento e das ações com as quais nos acostumamos e aceitamos o que existe para então ser possível a construção de novas formas de pensar e fazer. Este referencial é pertinente, para olhar e analisar o objeto desta investigação, à medida que considera as diversidades de produção de vida existentes, em nossos cotidianos, incluindo os territórios escolares.

Participaram da pesquisa, respondendo a um questionário semiestruturado: 10 cuidadores, 10 diretores, 10 assistentes educacionais e 13 professores, totalizando 43 participantes. 0 critério, para a inclusão dos participantes, foi ser professor, assistente educacional, diretor ou cuidador principal de crianças com idade até 10 anos com deficiência física ou múltipla e matriculada no ensino fundamental das escolas municipais de uma cidade do interior de Minas Gerais que possui 36 escolas municipais de educação. A partir de informações fornecidas pela secretaria municipal de educação, adotandose os critérios de inclusão, 14 crianças foram selecionadas para participarem da pesquisa, porém duas mães se recusaram, pois uma não possuía tempo disponível para a realização da entrevista e uma escola não conseguiu identificar a criança. Sendo assim, foram entrevistados profissionais de 10 escolas.

Os dados coletados foram submetidos à análise de conteúdo ${ }^{(11)}$. Trata-se de um conjunto de técnicas de análise das comunicações visando obter, por procedimentos sistemáticos e objetivos, de descrição do conteúdo das mensagens, elementos que permitem inferir conhecimentos relativos às condições de produção dessas mensagens ${ }^{(11)}$. Na fase inicial, denominada pré-análise, organizou-se o material. Foram feitas as transcrições de todas as entrevistas, realizado um primeiro contato com os textos. Posteriormente, realizou-se a leitura flutuante das entrevistas, captando o conteúdo de modo geral. Já na segunda etapa, realizaramse a referenciação dos índices e a elaboração de indicadores com recortes do texto e categorização, bem como a exploração e a preparação do material em análise. E, por fim, implementou-se a terceira etapa, na qual se desenvolveu a interpretação dos dados, discursos, estabelecimento de quadros de resultados, colocando em relevo as informações fornecidas pelas análises ${ }^{(11)}$. Esses procedimentos permitiram a construção de três categorias empíricas: a desarticulação entre os profissionais da educação e da saúde, a atenção à criança com deficiência no Sistema Único de Saúde (SUS) na perspectiva dos profissionais da educação e a família no contexto da inclusão escolar e a relação com a escola. Todas elas foram discutidas, considerando-se o referencial teórico metodológico adotado e evidências atuais sobre o objeto, nesse contexto, investigado.

Com o propósito de preservar a identidade dos participantes, estabeleceu-se o código E para cada entrevistado, seguido por A, P, D e C, para assistente educacional, professores, diretores e cuidadores, respectivamente. Foi designado a cada entrevistado a sequência numérica, de acordo com a realização das entrevistas, variando de 1 a 13 aos professores e de 1 a 10 para as demais categorias dos participantes. Utilizou-se a codificação, em toda a organização e análise do estudo, mantendo a mesma ordem.

A pesquisa foi desenvolvida atendendo ao disposto na resolução número 466 de 12 de dezembro de 2012 que trata de pesquisas envolvendo seres humanos. Foi aprovada pelo Comitê de ética da instituição proponente conforme o número CAAE 74009317.1.0000.5545. Antes da realização das entrevistas e da aplicação dos questionários, os 
participantes concederam a autorização para participação mediante aceite e assinatura do Termo de Consentimento Livre e Esclarecido e receberam uma via desse documento.

\section{RESULTADOS E DISCUSSÃO}

\section{Apresentação dos participantes}

Do total de 33 profissionais da educação participantes do estudo, dois eram do sexo masculino, a idade variou de 20 a 62 anos, o tempo de atuação entre 7 a 33 anos, sendo que quatro dos assistentes educacionais estavam cursando a graduação. Por meio dos dados, observou-se que a maioria dos profissionais possui tempo de atuação maior que 11 anos; esse fato demonstra que, quando a Lei no 13.146 de $2015^{(4)}$, que trata da inclusão da pessoa com deficiência foi estabelecida, a maioria dos educadores já se encontrava no campo de trabalho. Esse pode ser um dos motivos relacionados à dificuldade de adaptação à nova realidade dentro das salas de aula, uma vez que disciplinas relacionadas ao ensino de alunos com necessidades educacionais especiais são, ainda hoje, escassas no processo de formação de educadores.

Dos cuidadores, nove eram mães e 1 (uma) era avó da criança; oito tinham idade entre 20 a 40 anos, o grau de instrução do gestor da família foi, em sua maioria, até o ensino fundamental completo. Grande parte morava em casa própria, $70 \%$ tinham a renda familiar menor ou iguala quatro salários mínimos. Para a classificação econômica das famílias, foi utilizado o instrumento de Critério de Classificação Econômica Brasil (CCEB) da Associação Brasileira de Empresas de Pesquisa (ABEP), por meio de questionário validado ${ }^{(12)}$ a classificação econômica variou de $A 1$ a $E$, sendo que $A$ representa elevado poder de compra das famílias e E menor. Na presente pesquisa, a classificação das famílias foi $\mathrm{C} 1$, indicando baixo poder aquisitivo. Estudo afirma que a baixa condição socioeconômica e escolaridade materna estão associadas com maior prevalência de deficiências, pois, geralmente, pessoas com maior renda e escolaridade tendem a adotar comportamentos saudáveis com foco preventivo ${ }^{(13)}$. O tempo de inclusão escolar variou de 1(um) a cinco anos e, dentre os serviços que acompanham a criança estão: Atenção Básica, Associação de Pais e Amigos dos Excepcionais (APAE), Centro Estadual de Reabilitação e Readaptação (CRER) e a Policlínica do município.
Evidenciou-se que $40 \%$ dos participantes citaram a APAE como serviço de assistência à criança, instituição que tem uma avaliação positiva dos cuidadores, sobretudo, no que se refere ao trabalho conjunto entre a escola especial e a regular. Entretanto pesquisa ${ }^{(14)}$ situa que parcerias de coensino entre a escola especial e a regular ainda são pouco conhecidas ou praticadas nos municípios brasileiros.

\section{(Des)articulação entre profissionais da educação e da saúde}

A análise sinalizou uma desarticulação entre os profissionais de saúde e educação e ficou evidente que isso desfavorece o processo de inclusão das crianças. Os profissionais da educação expressaram sentir necessidade de orientações dos profissionais de saúde, para a realização dos cuidados que aquela criança necessita, no ambiente escolar e até mesmo sobre as peculiaridades da deficiência apresentada pelo aluno. No cenário desta pesquisa, em geral, o contato entre essas duas áreas acontece, por meio de relatórios, que, na maioria dos casos, não esclarece todas as dúvidas dos profissionais da educação. Além disso, quando julgam que algum aluno necessita de avaliação, é realizado o encaminhamento aos profissionais de saúde e orientações para a família buscar esse atendimento. Assim sendo, os profissionais da educação sugerem, em seus discursos, a necessidade de maior proximidade entre essas áreas, bem como a presença do profissional de saúde na escola para orientá-los sobre atividades de cuidado com as crianças e possibilidades do desenvolvimento infantil.

"Não. Não há troca nessas duas áreas não. Mais é só em forma de relatório, né? Mas assim, da gente encontrar com o profissional, da gente poder ter um esclarecimento maior, orientar a gente sobre como agir com aquela criança, como atender ela de forma melhor, pra ela avançar mais, não tem não. É relatório" (ED5).

"Então eu acho que tem, tinha que vim e explicar: olha essa deficiência acontece assim, ela precisa disso, precisa de tal cuidado, pra você tirar ele da cadeira você precisa pegar ele assim" (EP1).

Evidencia-se, na literatura, que é fundamental a colaboração dos profissionais de saúde, no âmbito escolar, e os enfermeiros sendo parte da equipe de ESF que possui as escolas, em sua área de adscrição, deveriam responsabilizarse e efetivar as ações do PSE, juntamente com os 
outros profissionais, a fim de facilitar a atuação dos educadores e promover a qualidade de vida das crianças. Entretanto, conforme evidenciado em estudo ${ }^{(15)}$, somente uma minoria de profissionais da saúde executa orientações e capacitações diretas aos educadores em seu trabalho pedagógico com as crianças. Dessa forma, depreende-se que a lacuna existente entre essas áreas acaba por fragilizar o trabalho dos educadores, que atuam, sem clareza e receosos, quanto ao convívio e manejo de seus alunos, além de dificultar o desenvolvimento potencial de cada criança.

Pesquisa encontrou resultados semelhantes aos aqui descritos e dispõe que a participação de profissionais da saúde, no ambiente escolar, acontece em momentos eventuais e há escassez de trocas de informações, as quais, quando apresentadas, ocorrem de forma indireta por caderno de recados, envio de relatórios ou por meio da família ${ }^{(16)}$. No entanto, entre os professores, há concordância unânime de que uma aproximação entre as duas áreas contribuiria, para o manejo das especificidades de seus alunos, desencadeando um acompanhamento integral e de maior segurança ao exercício de sua função.

A análise evidencia que os educadores sugerem programação de capacitações pelos profissionais da saúde sobre as deficiências e manejo com a criança para favorecer o processo de inclusão escolar. Além disso, destaca a necessidade da multidisciplinaridade, que é o apoio à criança com deficiência pelas diversas áreas de atuação, pois os educadores veem que a necessidade do aluno, para seu desenvolvimento, ultrapassa o pedagógico. Estes aspectos podem ser identificados, a seguir.

“É o que eu falei pra você antes, o município junto com a educação, junto com a saúde, fazer uma preparação dos profissionais da escola. Ou na escola ou na família, ou a família levar lá. Se não tiver tempo de ter reunião na escola, relatórios: Oh, o aluno tal precisa disso, disso e disso. Ás vezes, a gente faz as coisas achando que tá certo e tá errado" (EP2). "O profissional da área da educação, ele não tem a competência de trabalhar determinadas coisas é... questões que é necessário trabalhar muitas das vezes com essas crianças" (ED5).

Como os achados desta pesquisa, há evidência já publicada de que o trabalho conjunto da equipe multidisciplinar de crianças com deficiência é necessário pelo comprometimento que elas podem apresentar, em mais de uma área de adaptação e, aliado a isso, diagnósticos precoces poderiam levar a ações mais eficazes ${ }^{(17)}$. Assim, pontua-se que o trabalho conjunto entre educação e saúde poderia facilitar o entendimento dos educadores sobre as especificidades de seus alunos, em processos de inclusão e, em consequência, potencializar a elaboração e adaptação de seus recursos pedagógicos, oferecendo novas possibilidades de aprendizagem.

\section{A atenção à criança com deficiência no SUS na perspectiva dos profissionais da educação}

Verifica-se que um atendimento tardio pode desencadear atraso no desenvolvimento de uma criança, acarretando prejuízos para toda a sua vida ${ }^{(17)}$. Na ótica dos profissionais da educação, há certas dificuldades de atenção à criança com deficiência pelo SUS no cenário de investigação. Evidenciou-se, na análise, que muitas famílias não possuem condições econômicas, para realizar o acompanhamento na saúde suplementar e, quando conseguem pelo SUS, o tratamento é tardio, podendo não favorecer o desenvolvimento da criança em toda a sua potencialidade, conforme demonstram os enunciados abaixo:

"Temos alguns alunos aqui que necessitam de tratamento especializado e os SUS não têm condição de arcar, atender essas crianças, ficam na espera" (ED6). "É... A gente vê a dificuldade das famílias, né, porque a gente conversa, né, com as famílias, a gente chama pra conversar, trocar uma ideia, pra saber mais, às vezes, sobre a criança, o que tem sido feito por ela. E... O que a gente escuta é isso, que o município não atende, né? $E$ quando consegue marcar uma consulta, tipo assim: Às vezes, era uma coisa de emergência...Consegue marcar para daqui seis meses, daqui oito meses... E a criança vai perdendo com isso" (ED5).

As falas sinalizam que, no cenário de investigação, há dificuldades de atendimento pelo SUS. O Instituto de Pesquisa Econômica Aplicada (IPEA), em uma análise sobre a saúde brasileira, revelou que há demora no atendimento com ou sem especialista e falta de médico ${ }^{(18)}$, em concordância com os resultados desta pesquisa que revelam a dificuldade de acesso aos serviços de saúde, de acolhimento, atendimento em tempo hábil e longo tempo de espera. 
Além do atendimento, em tempo oportuno, as crianças necessitam receber um diagnóstico. Entretanto os professores apontam que há diagnósticos errôneos acerca das deficiências os quais comprometem a resolutividade das demandas apresentadas pelas crianças, e a falta de conhecimento sobre o diagnóstico da criança dificulta o trabalho:

" Hoje em dia, tá muito divulgado isso e há muitos diagnósticos errados. Pode ser que a criança tenha um bloqueio, uma dificuldade com determinada aprendizagem e seja considerada como deficiência, daí os erros de diagnósticos e muita coisa não acontecendo por causa disso" (ED2). "Que eu acho que deveria ter mais atendimento para essas crianças, melhores, fora as outras que não têm atendimento e não têm um laudo fechado, porque depende da rede pública, para fazer um diagnóstico, aí quando faz o diagnóstico já tá tarde; como diz, a criança já perdeu metade do ano, da vida escolar dela, então já tá tardia" (ED3).

É necessário que os profissionais da educação conheçam a situação de saúde da criança para que boas estratégias de aprendizagem sejam desenvolvidas. Entretanto tais profissionais justificam o não fazer $\mathrm{e}$ estratégias inadequadas pela ausência de diagnóstico. Esses achados permitem inferir que essa não seria justificativa, para impedir a inclusão escolar, pois se considera que, na inclusão escolar, a criança deva ser incluída especialmente com a valorização daquilo que ela é capaz de realizar e não em função da deficiência que apresenta. Os desafios assistenciais ao grupo infantil desta investigação devem ser considerados importantes subsídios, para o planejamento de estratégias, porém não deve ser justificativa para não realizar a inclusão. Pesquisa revela resultados semelhantes ${ }^{(16)}$, ao constatar que os professores veem, nos profissionais da saúde, uma possibilidade de aval, para o trabalho desenvolvido na sala de aula, por isso, acredita-se que o trabalho conjunto entre profissionais da saúde, educação e família seja imprescindível, para que a criança tenha chance de desenvolver, da melhor maneira possível, suas possibilidades, mas não deve ser visto como a única alternativa.

Os profissionais da educação entrevistados percebem, no cotidiano das escolas, que quanto mais precoce é realizado o diagnóstico, mais benefícios aquela criança terá e pode ter mais chances de desenvolver suas potencialidades.
Sugerem o atendimento de saúde qualificado à família da criança diagnosticada com deficiência, para que ela possa compreender melhor o contexto, no qual a criança se encontra e facilitar a aceitação pelos familiares e os cuidados com a criança. Estas afirmativas são exemplificadas, a seguir:

"Eu acredito que, no nosso país, nós precisamos melhorar a qualidade do serviço que pega essa criança bem já lá no início, né? Que vão ter os primeiros cuidados com a criança, porque nós sabemos da importância que essa deficiência, ela seja descoberta o mais rápido, porque à medida que a gente descobre que uma criança tem deficiência de forma mais rápida, nós vamos saber quais os serviços que essas crianças demandam para conseguirmos estimular para que ela possa ter né, uma vida acadêmica... E possa seguir a sua trajetória como as demais crianças ditas normais" (ED4).

"Igualzinho os pais terem um atendimento, porque eu acredito também que, para os pais, também, seja muito complicado, né, como é complicado pra nós aqui na escola lidar com essas crianças, para os pais é também. A aceitação, lidar, saber, né, diferenciar um do outro, acaba comparando e tudo, precisava do pai ter também um acompanhamento, a família ter um acompanhamento" ( EP3).

A análise sinaliza uma referência a um padrão tido como normal, que pode, em alguma medida, associar-se a uma expectativa de que pessoas com deficiência devem alcançar conquistas iguais aos demais indivíduos. Nesse sentido, as conquistas dessas crianças podem não ser valorizadas. Considerando o referencial teórico de escolha ${ }^{(10)}$ infere-se que os profissionais da educação devem ser motivados a problematizar a inclusão escolar como um direito social e a buscar sistematizações curriculares mais abertas, para fazer dialogar a apropriação de conhecimentos comuns e específicos, para os sujeitos com comprometimentos, sejam eles físicos, psíquicos, sensoriais ou intelectuais, e os com altas habilidades/super dotação. Neste processo, os educadores devem avançar e evitar reproduzir uma lógica do ensino, na qual coexiste um lado visível, ou seja, estudantes que trazem resultados dentro dos padrões preconizados e valorizados na escola, e o outro lado invisível, aqueles nos quais os educadores não encontram sentido para ensinar-lhes por acreditarem que sejam incapazes de produzir conhecimento. 
Em relação à assistência à saúde, os cuidadores relatam que $\mathrm{o}$ atendimento das crianças ocorre, em redes especializadas, como APAE, CRER, Associação de Deficientes do Oeste de Minas (ADEFOM) e referem-se à falta de especialistas no SUS.

"Os fisioterapeutas são todos particulares, porque... O fisioterapeuta do SUS não conhece o problema dele e, às vezes, nem consegue né, atender ele" (EC2). "- Os cuidados dele que ajuda ele mais é lá no CRER né que onde ele faz educação... Onde ele faz o... Fisioterapia, faz... É... Terapia Ocupacional, ele faz hidroterapia também" (EC1). "Na APAE, a fisioterapeuta, a terapia ocupacional, fisioterapia motora, psicóloga, nutricionista, fonoaudióloga, neurologista também. Tem a ADEFOM também, que é fisioterapia motora também. O CRER também, mas ela vai mais é no ortopedista mesmo" (EC7).

$\mathrm{O}$ fato de o atendimento das crianças com deficiência ocorrer, majoritariamente, em redes especializadas, pode contribuir para o seu distanciamento aos atendimentos ofertados pela ESF. A enfermagem, como ciência do cuidado, atuando na ESF, principalmente na prevenção de agravos e promoção da saúde, deveria realizar ações na escola voltadas para esse público. Entretanto uma revisão integrativa da literatura apontou diversas fragilidades na atenção primária à criança com deficiência e suas famílias o que, em alguma medida, contribuiu para que este profissional não exerça ações nas escolas, como a sobrecarga de trabalho; baixa comunicação e integração entre as diferentes profissionais; falta de educação permanente; assistência baseada no modelo biomédico; despreparo do profissional, entre outros ${ }^{(19)}$.

\section{A família no contexto da inclusão escolar e a relação com a escola}

A análise do conteúdo das entrevistas sugere que os profissionais da educação reconhecem a importância da família no processo de inclusão escolar e a necessidade de aceitação e compreensão de sua parte para que eles possam executar seu trabalho com a criança de maneira adequada. No entanto alguns relatam a dificuldade de aceitação da família, quanto ao diagnóstico da criança e às adaptações necessárias para ela, e outros relacionam essa atitude de negação com a falta de conhecimento sobre a deficiência e o processo de inclusão escolar, como expresso nos enunciados abaixo:
"Se a família não aceitar não tem como; a família é o facilitador da situação. Se ele não entrar de cabeça, se ele não fizer o cotidiano junto com a escola, porque essas crianças é a escola num todo: É a serviçal, é a cozinheira, é a família, é todo mundo. É a professora regente, é a professora de apoio, é o professor de educação física, é, são todos, é o todo. A escola sozinha não consegue" (EP8). "A maior dificuldade é com os pais, que, às vezes, os pais não procuram conhecer o quê que é a inclusão, o que que é... O quê que a criança tem, o quê que a criança precisa, sabe, procurar ajuda, procurar... A... Procurar ajudar a criança, porque, às vezes, não entende, mas também não procura" (EA1).

Estudo evidencia que a articulação entre a família e a escola favorece o processo de inclusão escolar. A articulação entre pais e professores possibilita a discussão sobre as necessidades da criança com condição crônica e favorece a construção de estratégias que contribuem para a formação de vínculo e socialização com as pessoas ao redor fortalecendo o processo de inclusão. No entanto é de responsabilidade da escola promover ações, a fim de estabelecer o vínculo com a família e assim contribuir para a evolução dessas crianças ${ }^{(20)}$.

A descoberta de uma deficiência no filho pode gerar sentimentos negativos, como raiva, desespero e desesperança em razão de a expectativa da família em relação ao desenvolvimento da criança ${ }^{(21)}$. Dessa forma, a situação inesperada vivenciada pela família poderá levar à dificuldade de aceitação da condição de que a criança possui interferindo no processo de inclusão escolar. Torna-se evidente a necessidade dos profissionais da saúde e da educação reconhecerem que esses sentimentos podem estar presentes e auxiliar a família a fim de minimizar as adversidades enfrentadas. A análise releva que há situações em que as famílias aceitam a deficiência, mas mostram-se desinteressadas ao processo de inclusão escolar. Esse desinteresse é evidente, também, quando a família não procura a assistência à saúde necessária à criança.

Os discursos mostram que o diálogo com a família, apesar de escasso no cenário de investigação, é, ainda assim, um facilitador para o trabalho na escola. Identifica-se como um desafio no cotidiano do ensino, na percepção dos profissionais da educação, a falta de limites e regras que deveriam fazer parte da educação dos pais com os filhos e, neste sentido, algumas 
crianças possuem dificuldades em atender às rotinas e regras estabelecidas pela escola. Podem ser identificadas nos enunciados a seguir:

"Há uma parceria né, entre a família, a escola, os profissionais. Sempre que necessário a gente procura a família, a família procura a escola, os profissionais também que acompanham essas crianças também tão sempre é... Procurando a escola também quando necessário, nós também da escola procuramos esses profissionais; pra ter um contato né, pra saber como que tá" (EP11). "É muito difícil pra tá fazendo uma criança, no caso, até mesmo pra tá seguindo um pouco, vamos falar, regras da escola. Até mesmo porque precisa, não pode tá deixando vir pra escola, no meu ponto de vista, não pode deixar a criança vir pra escola e fazer, todos querer o que a criança quer, eu acho que ela precisa saber que ela está em um ambiente escolar, né? Que tem mais crianças ao redor dela também" (EA9-).

A escola é reconhecida como um espaço que deve ofertar à criança oportunidades para que ela desenvolva habilidades que Ihe facilitem o convívio com outras crianças, processo esse voltado para a socialização no geral. Junto a essa realidade está a convicção de que a parceria entre a família e a escola potencializa o aprendizado da criança. A inclusão escolar fica fragilizada pela falta de união existente entre os pais e a escola ${ }^{(22)}$.

A análise do conteúdo dos discursos demonstra uma perspectiva positiva das cuidadoras em relação ao processo de inclusão escolar. Apesar do receio de alguns pais, no início, pelo sentimento de insegurança ao colocar a criança na escola, eles relatam o bom acolhimento dos profissionais e interesse em colaborar com as adaptações para seus filhos.

"Bem, com um ano e três, quatro meses que ele foi, eu acho que foi mais complicado pra mim enquanto mãe, porque eu tinha muito medo do que poderia acontecer, porque ele é uma criança com visão subnormal, ele não fala. Então eu acho que eu demorei mais a adequar do que ele, mas com três meses ele, três, quatro meses ele tava bem ambientado na escola"(EC8).

"Foi tudo tranquilo, as cuidadoras também foi tudo atenciosa. Até choram quando vai largar ela. Ela foi a primeira cadeirante a estudar aqui. Eles preocupou muito em adaptar ali pra ela. Não teve nenhum não, sempre foi bem tranquilo, eles são atenciosos com ela, procurou desde o início, principalmente nessa escola aqui, fez até uma reunião com a gente pra poder entender os cuidados que tem que ter com ela e tudo mais, né? É bem tranquilo. A gente gostou bastante" (EC7).

Pesquisa ${ }^{(23)}$ em que se abordou a concepção dos pais sobre o processo de inclusão confirma que houve uma perspectiva positiva com destaque em mudanças, como a aprendizagem pedagógica, alteração no comportamento e felicidade da criança em estar no ambiente escolar. Os resultados do presente estudo corroboram com esses achados, uma vez que os pais mostraram satisfação, sobretudo, ao perceberem a alegria da criança e ao reconhecerem o trabalho dos profissionais com seus filhos.

O sentimento de insegurança diante da trajetória que a criança seguirá, no processo de inclusão, deve-se ao fato de que os pais presumem que o ambiente escolar seja um ambiente hostil aos seus filhos, pelo preconceito, condições da escola e elevado número de matrículas $^{(24)}$. No entanto esse receio tende a desaparecer, quando os pais acompanham a dedicação dos professores, no processo da educação infantil, e o efeito direto do seu trabalho no desenvolvimento de seus filhos ${ }^{(15,24)}$.

Entretanto revelou-se, na análise, uma fragilidade na articulação entre a família e a escola no processo de inclusão escolar. Por parte da família, há alguns fatores que podem influenciar na baixa participação da vida escolar do filho, como a baixa autoestima, desvalorização dos recursos da escola e idealizar a escola como detentora do saber formal. Além disso, pode estar relacionada à crença de que vão interferir na independência e autonomia de seus filhos, experiência escolar dos pais que não foi bem sucedida e até mesmo aos aspectos financeiros e ao horário de atendimento da escola, fazendo com que se mantenham distantes ${ }^{(25)}$.

\section{CONCLUSÃO}

Há uma fragilidade na articulação entre os profissionais da saúde, da educação e famílias no cenário de investigação no processo de inclusão escolar. Identificou-se que o envolvimento da ESF e dos profissionais enfermeiros poderia favorecer o processo de inclusão, contudo é necessário que os atores envolvidos consigam ter clareza de quais as funções podem exercer na vida dessas crianças buscando seu desenvolvimento, bem como construindo conjuntamente, mesmo que 
todas as respostas não estejam claras. Identificou-se que é oportuna a inserção ou articulação efetiva da enfermagem com a escola, para apoiar os profissionais da educação, mediante as necessidades e cuidados específicos demandados por crianças com deficiências. Além disso, é primordial que os currículos da graduação desses profissionais e da educação abordem essa temática com conteúdos práticos e teóricos.

Soma-se a isso a participação familiar, no âmbito da escola, para alcançar melhorias no processo de socialização da criança; a equipe multidisciplinar de saúde, presente no ambiente escolar, visando à oferta de conhecimento e maior segurança aos educadores no convívio com as crianças em inclusão. Além disso, a oferta de serviços pelo SUS, no cenário de investigação, precisa ser viabilizada, a fim de contemplar as necessidades e demandas da criança com deficiência e contribuir para o alcance de melhor qualidade de vida e sua participação no ambiente escolar.

Evidenciaram-se, neste estudo, as dificuldades presentes entre as áreas da saúde e educação no processo de inclusão escolar e a necessidade de criar estratégias que minimizem a desarticulação. Destaca-se que estudos nessa área ainda são incipientes o que justifica esta pesquisa descritiva e identifica-se a necessidade de novas pesquisas acerca do tema abordado. Por fim, reconhecem-se as seguintes limitações da presente pesquisa: a não inclusão de profissionais da saúde e de escolas de ensino privado.

\section{REFERÊNCIAS}

1- UNICEF. Situação Mundial da Infância 2013: Crianças com deficiência. Brasília: UNICEF; 2013.

2- Ministério da Saúde (BR). Política Nacional de Atenção Integral à Saúde da Criança: orientações para implementação. Brasília: Ministério da Saúde; 2018. Disponível em: http://www.saude.pr.gov.br/arquivos/File/Politic a_Nacional_de_Atencao_Integral_a_Saude_da_C rianca_PNAISC.pdf

3- Brasil. Presidência da República, Subchefia para Assuntos Jurídicos. Lei no 12796 de 04 de abril de 2013. Altera a Lei no 9.394, de 20 de dezembro de 1996, que estabelece as diretrizes e bases da educação nacional, para dispor sobre a formação dos profissionais da educação e dá outras providências. Brasília, DF; 2013. Disponível
http://www.planalto.gov.br/ccivil_03/_Ato20112014/2013/Lei/L12796.htm.

4- Brasil. Presidência da República, Subchefia para Assuntos Jurídicos. Lei no 13146 de 06 de julho de 2015. Institui a Lei Brasileira de Inclusão da Pessoa com Deficiência (Estatuto da Pessoa com Deficiência). Brasília, DF; 2015. Disponível em:

http://www.planalto.gov.br/ccivil_03/_Ato20152018/2015/Lei/L13146.htm.

5- Silva NA, Carvalho BGE. Compreendendo o Processo de Inclusão Escolar no Brasil na Perspectiva dos Professores: uma Revisão Integrativa. Rev. bras. educ. espec.2017 Abr-Jun [Citado em 05 mar 2019]; 23(2):293308.DOI:https://doi.org/10.1590/s141365382317000200010.

6-Garcia PMA, Diniz RF, Martins MFA. Inclusão Escolar No Ensino Médio: Desafios da Prática Docente. Rev Iber Amer de est em ed. 2016 [Citado em 2019 Mar 05]; 11(2):1000-1016. DOI: https://doi.org/10.21723/riaee.v11.esp2.p10001016.

7- Oliva DV. Barreiras e recursos à aprendizagem e à participação de alunos em situação de inclusão. Psicol. USP. 2016. [Citado em 05 mar 2019]; 27(3): 492-502. DOI: https://doi.org/10.1590/0103656420140099.

8-Secretaria da Saúde (RS). Departamento de Ações em Saúde Seção de Saúde da Criança e Adolescente. Programa Saúde na Escola(PSE) Manual de orientações. Rio Grande do Sul; Secretaria da Saúde; 2019. Disponível em: https://saude.rs.gov.br/upload/arquivos/carga20 190747/09084757-10-manualorientacoes-pseciclo-2019-2020.pdf.

9-Mack N, Macqueen CWKM, Guest G, Namey E.Qualitative Research Methods: A Data Collector's Field Guide. North Carolina: Fam. Health Int. 2011 [Citado em 05mar 2019]. Disponível em: https://www.fhi360.org/sites/default/files/media /documents/Qualitative\%20Research\%20Method s\%20-

\%20A\%20Data\%20Collector\%27s\%20Field\%20Gui de.pdf.

10- Santos BS. A Gramática do Tempo: para uma nova cultura política. São Paulo: Editora Cortez; 2006.

11-Bardin L. Análise de conteúdo. 4ạed. Lisboa: Edições 70; 2011.

12-Associação Brasileira de Empresas de Pesquisa. Critérios de classificação econômica 
Brasil. ABEP. 2016. [Citado em 05 mar 2019]. Disponível em: www.abep.org/Servicos/Download.aspx?id=12. 13-. Felicíssimo MF, Friche AAL, Xavier CC, Proietti FA, Neves JAB, Caiaffa WT. Posição socioeconômica e deficiência: "Estudo Saúde em Belo Horizonte, Brasil". Ciênc Saúde Colet. 2017 [Citado em 22 jan 2019]; 22(11):3547-3556. DOI: https://doi.org/10.1590/1413-

\subsection{7.}

14- Neves LR, Rahme MMF, Ferreira CMRJ. Política de Educação Especial e os Desafios de uma Perspectiva Inclusiva. Educ. Real. 2019. [Citado em 05 mar 2019]; 44(1), e84853. DOI: https://doi.org/10.1590/2175-623684853.

15- Campos CCP, Silva FCP, Ciasca SM. Expectativa de profissionais da saúde e de psicopedagogos sobre aprendizagem e inclusão escolar de indivíduos com transtorno do espectro autista. Campinas: Psicopedagogia. $2018 \mathrm{Fev}$ [Citado em 05 mar 2019]; 35(106):3-13. Disponível em: http://pepsic.bvsalud.org/pdf/psicoped/v35n106 /02.pdf.

16- Silva CCB, Molero ESS, Roman MD. A Interface entre Saúde e Educação: percepções de educadores sobre educação inclusiva. Psicol. Esc. Educ. 2016 Jan-Abr [Citado em 05 mar 2019]; 20(1):109-115.

DOI: https://doi.org/10.1590/2175-353920150201934. 17- Schwartzman JS, Lederman VRG. Deficiência intelectual: causas e importância do diagnóstico e intervenção precoces. Inc. Soc.. 2017 Jan-Jun [Citado em 05 mar 2019]; 10(2):17-27. Disponível em:

http://revista.ibict.br/inclusao/article/view/4028. 18- BRASIL. Ministério do Planejamento. Instituto de Pesquisa Econômica Aplicada. Pesquisa sobre a saúde brasileira. Brasília. 2011 [Citado em 05 mar 2019]. Disponível em: http://www.ipea.gov.br/portal/index.php?option $=$ com_alphacontent\&ordering $=3 \&$ limitstart $=5300$ \&limit $=10 \& \mid$ temid $=0$.

19-Amorim EG, Liberali R, Medeiros Neta OM. Avanços e desafios na atenção à saúde de pessoas com deficiência na atenção primária no brasil: uma revisão integrativa. HOLOS.2018 Jan [Citado em 05 mar 2019]; 34(1):224-236. Disponível em: www2.ifrn.edu.br/ojs/index.php/HOLOS/article/d ownload/5775/pdf.

20- Pinto MB, Soares CCD, Santos NCCB, Pimenta EAG, Reichert APS, Collet N. Percepção de mães acerca da inclusão escolar de crianças com doença crônica.Rev. enferm. UFPE on line. 2017 Mar [Citado em 05 mar 2019];11(3):1200-1206. DOI: $\quad$ 10.5205/reuol.10544-93905-1RV.1103201710.

21- Cerqueira MMF, Alves RO, Aguiar MGG. Experiências vividas por mães de crianças com deficiência intelectual nos itinerários terapêuticos. Ciênc Saúde Colet. 2016 Jun [Citado em 05 mar 2019]; 21(10): 3223-3232. DOI: https://doi.org/10.1590/1413-

812320152110.17242016.

22- Lazzaretti B, Freitas AS. Família e escola: o processo de inclusão escolar de crianças com deficiências. Cad.Inters. 2016 Jan-Dez [Citado em 05 mar 2019]; 5(6):1-13. Disponível em: https://www.uninter.com/cadernosuninter/index .php/intersaberes/article/.../376/381.

23- Lemos ELMD, Salomão NMR, Aquino FSB, Agripino-Ramos CS. Concepções de pais e professores sobre a inclusão de crianças autistas.Fractal rev. psicol.2016 Set-Dez [Citado em 05 mar 2019]; 28(3):351-361. DOI: https://doi.org/10.1590/1984-0292/1229.

24- Benitez P, Domeniconi C. Inclusão Escolar: o Papel dos Agentes Educacionais Brasileiros. Psicol.ciênc. prof. 2015 Out-Dez [Citado em 05 mar 2019]; 35(4):1007-1023.DOI: https://doi.org/10.1590/1982-3703000652014.

25- Silva AM, Caral LSA, Martins MFA. Abordagem relacional entre família e escola inclusiva sob a perspectiva de professores. Interf. Educ.2016. [Citado em 21 out 2019] 19(7):191-205. DOI: https://doi.org/10.26514/inter.v7i19.1065.

Nota: Financiamento do Conselho Nacional de Desenvolvimento Científico e Tecnológico - CNPq. Bolsa de Iniciação científica.

Recebido em: 29/10/2019

Aprovado em: 08/04/2020

Endereço de Correspondência:

Patrícia Pinto Braga

Rua Sebastião Gonçalves Coelho, 400. Chanadour, Divinópolis - MG. Brasil. CEP: 35501262.

E-mail: patriciabragaufsj@gmail.com 